\title{
Immune dysregulation-inflammatory bowel disease-arthritis-recurrent infections syndrome
}

INSERM

\section{Source}

INSERM. (1999). Orphanet: an online rare disease and orphan drug data base. Immune dysregulation-inflammatory bowel disease-arthritis-recurrent infections syndrome. ORPHA:238569

Immune dysregulation-inflammatory bowel disease-arthritis-recurrent infections syndrome is a rare immune dysregulation disease with immunodeficiency characterized by severe, progressive infantile onset inflammatory bowel disease with pancolitis, perianal disease (ulceration, fistulae), recurrent respiratory, genitourinary and cutaneous infections, arthritis and a high risk of B-cell lymphoma. 